\title{
Density Functional Study on Benzene, Toluene, Ethylbenzene and Xylene Adsorptions on $\mathrm{ZnO}(100)$ Surface
}

\author{
Nugraha ${ }^{1,2}$, Adhitya Gandaryus Saputro ${ }^{1,2,}$, Mohammad Kemal Agusta ${ }^{1,2}$, Fiki Taufik Akbar ${ }^{3}$, Aditya Dimas \\ Pramudya ${ }^{4}$ \\ ${ }^{1}$ Advanced Functional Materials Research Group, Institut Teknologi Bandung, Jl.Ganesha 10, Bandung \\ 40132, Indonesia \\ ${ }^{2}$ Research Center for Nanosciences and Nanotechnology, Institut Teknologi Bandung, Jl. Ganesha 10, \\ Bandung 40132, Indonesia \\ 3 Theoretical High Energy Physics and Instrumentations Research Group, Institut Teknologi Bandung, \\ Jl.Ganesha 10, Bandung 40132, Indonesia \\ ${ }^{4}$ Ecology Research Group, Institut Teknologi Bandung, Jl.Ganesha 10, Bandung 40132, Indonesia
}

*Corresponding author email: ganda@tf.itb.ac.id

Received: 8 Mar 2019; Accepted: 29 May 2019; Available online: 5 Jun 2019

\begin{abstract}
We study the interaction between benzene, tolvene, ethylbenzene and xylene (BTEX) molecules with $\mathrm{ZnO}$ (100) surface by means of density functional theory-based calculations. We find that these interactions result in the physical adsorptions of BTEX gases with adsorption distances larger than $2 \AA$. These adsorptions are governed by the van der Waals interaction instead of the covalent interaction. We also find that the trend of the strength of $\mathrm{BTX}$ adsorptions on $\mathrm{ZnO}(100)$ surface $\left(\left|E_{\text {ad }}^{\text {benzene }}\right|<\left|E_{\text {ad }}^{\text {toluene }}\right|<\left|E_{\text {ad }}^{\text {xylene }}\right|\right)$ is in line with the experimental trend of sensitivity of ZnO material towards BTX gases (benzene < tolune < xylene). We explain this relation by using one of the sensing mechanism within the ionosorption model. By using this relation, we also predict that the response of $\mathrm{ZnO}$ towards ethylbenzene will be similar to the response towards tolvene since these two molecules have similar adsorption energies on $\mathrm{ZnO}(100)$ surface.
\end{abstract}

Keywords: adsorption; benzene; tolvene; ethylbenzene; xylene; density functional theory; $\mathrm{ZnO}(100)$ surface

\section{INTRODUCTION}

Volatile organic compounds (VOCs) are some of the main sources of air pollution that can cause serious harms to human health (Brook, 2008). Even though the human nose in general can sense the presence of odorous gases like VOCs, in some cases, it might not be able to sense them especially when the concentration of the gases are quite low or when the gases are mixed with other gases (Mirzaei, Kim, Kim, \& Kim, 2018). Benzene, toluene, ethylbenzene and xylene (BTEX) are benzene-based VOC compounds that are colorless and have peculiar odors (Fishbein, 1985; K. H. Kim, Pandey, \& Pal, 2009; Szczurek, Maziejuk, Maciejewska, Pietrucha, \& Sikora, 2017). Because of their toxicity and carcinogenicity, a relatively long direct exposure of these gases to our human body, even at low concentration, can cause very serious threats and might even lead to death (Duarte, R, C, \& L, 2001; Gist \& Burg, 1997; Gromiec \& Piotrowski, 1984; Jeong et al., 2017; Pyta, 2006; Robert Schnatter et al., 2010). Moreover, their similar characteristics makes the BTEX gases hard to be distinguished. Therefore, accurate identification of BTEX gases is very crucial for human safety.

Resistive-based gas sensor is a type of gas sensor which has many advantages including high sensitivity, high stability, portability, low power consumption, and low production cost (Gurlo, 2006; Gurlo \& Riedel, 2007; Miller, Akbar, \& Morris, 2014; Mirzaei et al., 2018). The main sensing part of this sensor is frequently made from semiconductor metal-oxide (Debataraja et al., 2017; Gurlo \& Riedel, 2007; Iqbal et al., 2014; Miller et al., 2014; Mirzaei et al., 2018; Muchtar, Septiani, Iqbal, Nuruddin, \& Yuliarto, 2018; Rifai et al., 2011; Septiani, Yuliarto, Nugraha, \& Dipojono, 2017; Septiani et al., 2018, 2015; Septiani \& Yuliarto, 2016; Yuliarto, Gumilar, \& Septiani, 2015; Yuliarto, Iqbal, \& Nuruddin, 2013; Yuliarto, Ramadhani, Nugraha, Septiani, \& Hamam, 2017; Yuliarto, Nulhakim, et al., 2015). Zinc oxide ( $\mathrm{ZnO})$ is a wide gap metal-oxide that has been used in many resistive-based gas sensor application, including benzene, toluene and xylene (BTX) sensors. Numerous efforts have been given to engineer the morphology and composition of $\mathrm{ZnO}$ nanomaterial to enhance its sensitivity toward BTX gases (Acharyya \& Bhattacharyya, 2015; Mirzaei et al., 2018; Nagaraju, Vijayakumar, Reddy, \& Ramana Reddy, 2018; Septiani et al., 2017; Wang et al., 2013; Woo, Kwak, Chung, \& Lee, 2014). Unfortunately, there is still no clear consensus on the detail sensing mechanism on this material for large size molecules like BTEX. This is caused by the 
lack of understanding about the fundamental interaction between $\mathrm{ZnO}$ surface and large size molecules.

In this work, we theoretically study the interaction between $\mathrm{ZnO}$ surface and BTEX gases using density functional theory-based calculations (Hohenberg \& Kohn, 1964; Kohn \& Sham, 1965). We elucidate the detail mechanism that governs the adsorption of BTEX gases on $\mathrm{ZnO}$ surface. We use $\mathrm{ZnO}(100)$ as the surface model for studying this interaction. The (100) surface is chosen because this is one of the most stable surface facet of $\mathrm{ZnO}$ and the main surface facet of $\mathrm{ZnO}$ sensor with nanorod and nanowire morphologies (Acharyya \& Bhattacharyya, 2015; Diebold, Koplitz, \& Dulub, 2004; Huang \& Wan, 2009; Kaneti, Yue, Jiang, \& Yu, 2013; Mirzaei et al., 2018; Spencer, Wong, \& Yarovsky, 2012; Wang et al., 2013; Yuliarto et al., 2017; Zhu, Xie, Wang, Huang, \& Hu, 2004). The results from this study will contribute to a deeper understanding about the fundamental interaction of $\mathrm{ZnO}$ surface with large size molecules like BTEX and its implications on the involved sensing mechanism.

\section{EXPERIMENTAL SECTION \\ Computational Details \\ 1. Surface model}

The widely accepted sensing mechanism of resistivebased semiconductor metal oxide-based gas sensor involves the exposure of $\mathrm{O}_{2}$ gas to the sensor surface at high temperature prior to the exposure of target gas (Gurlo \& Riedel, 2007). During the exposure of oxygen gas, the gas interacts with the semiconductor surface and form various ionic oxygen species such as $* \mathrm{O}^{2-}$, $* \mathrm{O}^{-}$or $* \mathrm{O}^{2-}$. These adsorbed ions later will react with the target gas and the change in electronic resistance during this interaction is interpreted as the response of the sensor. Therefore, the presence of such ionic oxygens is very crucial for metal oxide-based gas sensor. The sensing process will be facile if the incoming $\mathrm{O}_{2}$ gas could interact well with the metaloxide surface.

In the case of $\mathrm{ZnO}$ material, a theoretical study by Yan et al demonstrates that the incoming $\mathrm{O}_{2}$ molecule cannot interact well with a perfect $\mathrm{ZnO}(100)$ surface (Yan, AlJassim, \& Wei, 2005). The $\mathrm{O}_{2}$ chemisorption can only be occurred on the reduced $\mathrm{ZnO}(100)$ surface in which the surface has pre-exist $\mathrm{O}$ surface vacancies (Xu, Zhang, \& Tong, 2010; Yan et al., 2005). In such situation, one O atom of the incoming $\mathrm{O}_{2}$ molecule will occupy and heal the $\mathrm{O}$ vacancy site and the other $\mathrm{O}$ atom will stay adsorbed on the surface. This singly adsorbed $\mathrm{O}$ atom can easily move on the $\mathrm{ZnO}$ surface. It is speculated that this *O will move and heal the nearest $\mathrm{O}$ vacancy site of the surface (Yan et al., 2005). Therefore, after the $\mathrm{ZnO}(100)$ surface is exposed by $\mathrm{O}_{2}$ gases for a period of time, it is very likely that most of the $\mathrm{O}$ vacancies on the surface are healed by $\mathrm{O}_{2}$ and this will leave us with a perfect $\mathrm{ZnO}(100)$ surface. Due to this reason, instead of using reduced $\mathrm{ZnO}(100)$ surface, we use the perfect $\mathrm{ZnO}(100)$ as a surface model for studying the interaction of $\mathrm{ZnO}(100)$ with BTEX gases. The model of unit cell of $\mathrm{ZnO}(100)$ is shown in Figure 1.

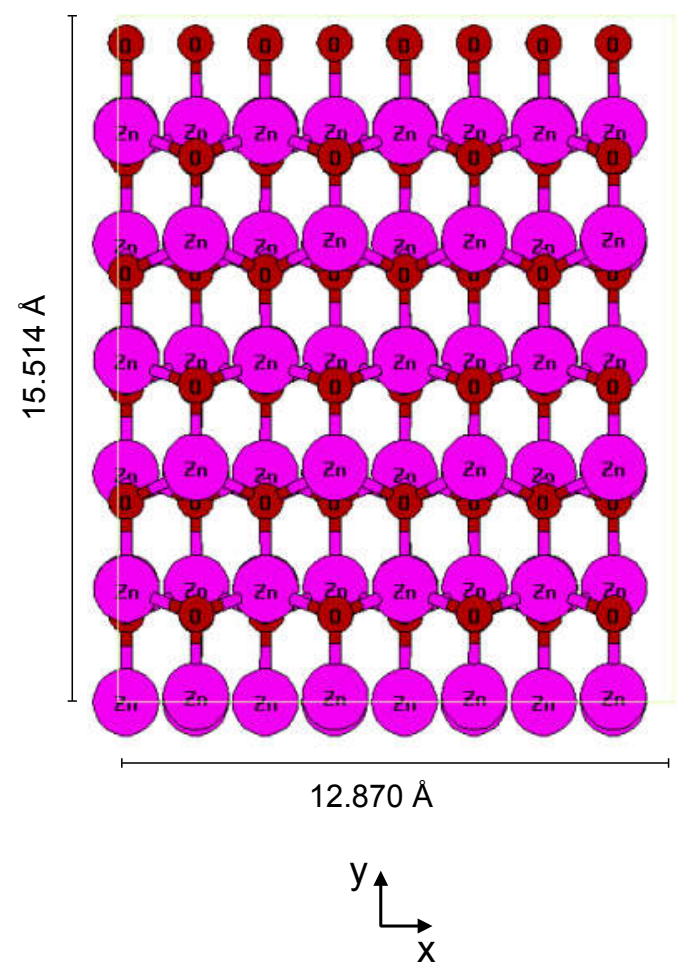

(a)
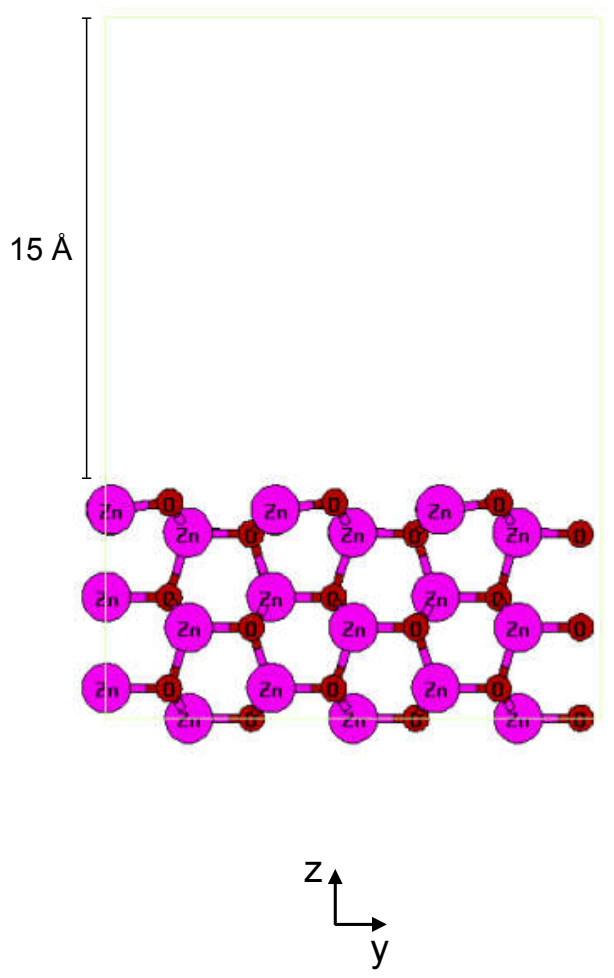

(b)

Figure 1. The top view (a) and side view (b) of unit cell model of perfect $\mathrm{ZnO}(100)$ surface. 


\section{DFT Calculations}

We investigate the adsorption of BTEX gases on $\mathrm{ZnO}(100)$ surfaces using density functional theory-based (DFT) calculations (Jung et al., 2006; Perdew, Burke, \& Ernzerhof, 1996a). Spin-polarized DFT calculations is performed using the Quantum-Espresso 5.4 (Giannozzi et al., 2009). Exchange and correlation effects are incorporated within the generalized gradient approximation, using the Perdew-Burke-Ernzerhof (PBE) functional (Perdew, Burke, \& Ernzerhof, 1996b). We use plane wave basis sets with 42 Ry cut-off energy. Valencecore interactions are represented by the projector augmented wave formalism (PAW) (Blöchl, 1994). All of the PAW potentials are taken from the Quantum-Espresso database. For geometrical optimization, the integration in Brillouin-zone is done only at gamma point since the unit cell size is quite large. For electronic structure analysis, the integration in Brillouin-zone is performed with a $4 \times 4 \times 1$ $\mathrm{k}$-points mesh. Hubbard-U correction is added by amount of $7.5 \mathrm{eV}$ for $\mathrm{Zn} 3 d$ states, following refs. (Erhart, Albe, \& Klein, 2006; Tang \& Luo, 2013). The calculation for isolated molecule is done in a $30 \AA$ x $30 \AA$ x $30 \AA$ cubic cell at the gamma point. The effect of van der Waals interaction is described using the semi-empirical correction scheme of Grimme (DFT-D2) (Grimme, 2006). The systems are relaxed until the residual force on each atomic component is less than $0.025 \mathrm{eV} / \AA$.

The non-polar $\mathrm{ZnO}$ (100) surface is modelled by repeated slab approach where the slabs are separated by vacuum space of about $15 \AA$. The slab model contains six layers of $\mathrm{Zn}-\mathrm{O}$ using a 4 × 3 supercell. The usage of large surface area for the supercell model is required to accommodate the adsorption sites for BTEX molecules. In all of the adsorption cases, atoms in adsorbed molecules and in two topmost $\mathrm{Zn}-\mathrm{O}$ layer are fully relaxed during optimization, while the rest are fixed in their bulk positions We consider various adsorption sites and conformations for BTEX adsorption on $\mathrm{ZnO}(100)$ surface. However, we will only discuss the most stable adsorption configurations for each BTEX molecules. The adsorption energy $\left(E_{a d}\right)$ of a molecule on $\mathrm{ZnO}(100)$ surface is defined as:

$$
E_{a d}=E_{\text {system }}-\left(E_{\text {surf }}+E_{\text {mol }}\right),
$$

where $E_{\text {system }}$ corresponds to the total energy of an adsorption system, $E_{\text {surf }}$ corresponds to the total energy of a clean $\mathrm{ZnO}(100)$ surface and $E_{\text {mol }}$ corresponds to the total energy of an isolated molecule. Visualization of atomic structures and charge density are done by using Xcrysden software (Kokalj, 2003).

\section{RESULTS AND DISCUSSION}

The calculated adsorption energies and adsorption distances of the most stable BTEX adsorption configurations on $\mathrm{ZnO}(100)$ surface are presented in Table 1. We compare the value of adsorption energies with and without dispersion correction. Many studies have demonstrated that dispersion correction is very important for studying the adsorption of benzene and larger molecules on metal (Lakshmikanth, Ayishabi, \& Chatanathodi, 2017; Liu et al., 2013; Liu, Tkatchenko, \& Scheffler, 2014; Reckien, Eggers, \& Bredow, 2014; Sabbe, Laín, Reyniers, \& Marin, 2013; Waldmann et al., 2012; Yildirim, Greber, \& Kara, 2013) and metal-oxide (Dzade, Roldan, \& de Leeuw, 2014; H. S. D. Kim, Yang, Qi, \& Rappe, 2017; Yang, Qi, Kim, \& Rappe, 2018) surfaces. The inclusion of this dispersion correction could give adsorption configurations and adsorption energies which are in agreement with experimental results.

In our system, the dispersion correction does not alter the molecular adsorption sites, but it decreases the adsorption distances and significantly increases the value of adsorption energies. We find that the inclusion of dispersion correction not only increases the absolute value of the adsorption energies, but also changes the trend of adsorption energies. Without the dispersion correction, the adsorption energy of benzene is stronger than that of ethylbenzene, but this trend is switched when the dispersion correction is activated. This result shows that the inclusion of dispersion correction is indeed very crucial for studying the selectivity and sensitivity of a sensing material towards large molecules like in our system, since these properties greatly depend on the trend of adsorption energies of the molecules.

The adsorption configurations and relative energies of the three most stable BTEX adsorptions on $\mathrm{ZnO}(100)$ surface are presented in Figures $2 \mathrm{a}-\mathrm{d}$. We find that vertical molecular adsorption configurations are energetically less favourable for BTEX adsorption configurations. The BTEX molecules prefer to be adsorbed parallel to the surface. In general, the difference in relative energies for parallel BTEX adsorption configurations are not so significant. This indicates that the contour of potential energy surface (PES) for BTEX adsorptions are quite flat as in the case of benzene adsorption on coinage metal surfaces (Liu et al., 2013; Reckien et al., 2014). Therefore, it becomes not so obvious how to unambiguously identify the most stable adsorption configuration. Due to this, for the sake of continuing the discussion, the adsorption configurations which give the lowest relative energies on each BTEX-ZnO(100) systems will be assigned as their most stable configurations.

Important parameters and adsorption configurations of the most stable BTEX adsorptions on $\mathrm{ZnO}(100)$ surface are presented in Table 2 and Figure 3. In their most stable adsorption configurations, the BTEX molecules adsorbed on top of the uppermost layer of $\mathrm{Zn}-\mathrm{O}$ dimer. The adsorption distances of BTEX molecules are quite large, $d_{\text {surf-mol }}>2 \AA$. The closest distance in BTEX-ZnO(100) interactions are mainly from the hydrogen bond between the $\mathrm{H}$ atom from the benzene ring of BTEX molecules and $\mathrm{O}$ atom of the topmost $\mathrm{ZnO}$ layer. These data suggest that the BTEX adsorptions on $\mathrm{ZnO}(100)$ surface are in the physisorption states. 
Table 1. Adsorption energies of BTEX gases on $\mathrm{Zn}(100)$ surface with and without long range dispersion correction.

\begin{tabular}{lcccc}
\hline \multirow{2}{*}{ Adsorbate } & \multicolumn{2}{c}{$E_{\text {ad }}(\mathrm{eV})$} & \multicolumn{2}{c}{$d_{\text {surf-mol }}(\AA)$} \\
\cline { 2 - 5 } & GGA-PBE & with DFT-D2 & GGA-PBE & with DFT-D2 \\
\hline \hline Benzene & -0.31 & -0.96 & 2.285 & 2.085 \\
Toluene & -0.38 & -1.17 & 2.456 & 2.389 \\
Ethylbenzene & -0.30 & -1.16 & 2.205 & 2.142 \\
Xylene & -0.45 & -1.35 & 2.209 & 2.048 \\
\hline
\end{tabular}
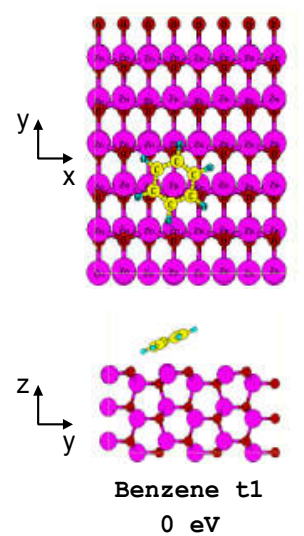

$0 \mathrm{eV}$
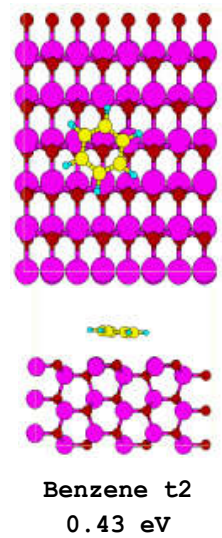

(a)
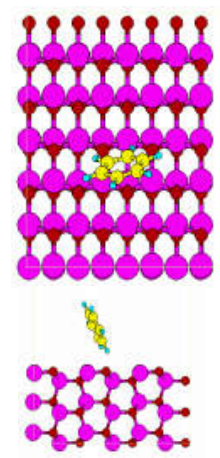

Benzene $t 3$ $0.53 \mathrm{eV}$
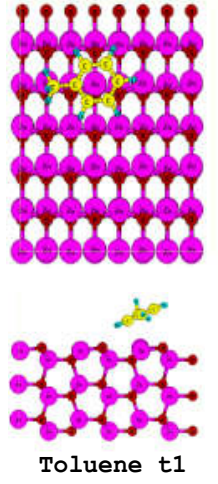

$0 \mathrm{eV}$
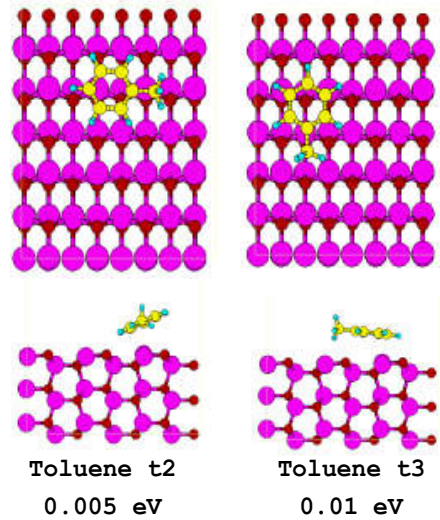

(b)
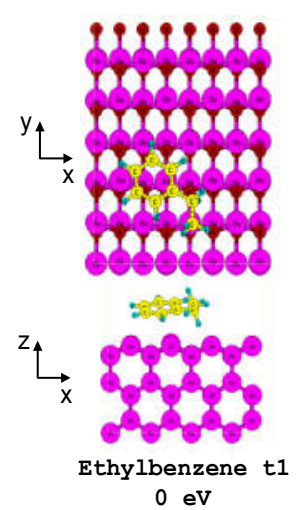

$0 \mathrm{eV}$
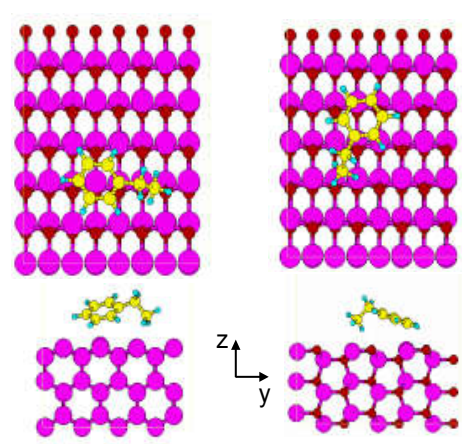

thylbenzene t2

(c)

$0.11 \mathrm{eV}$
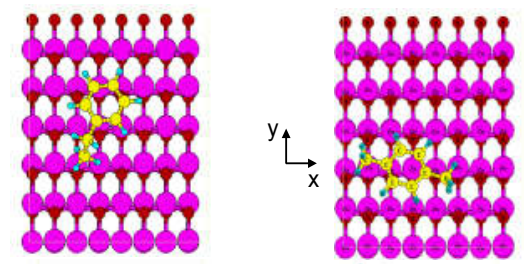

ispes

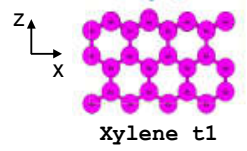

$0 \mathrm{eV}$

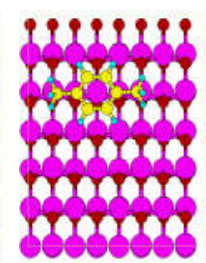

LPReg?



10010

monen

nomon

gerene

2.

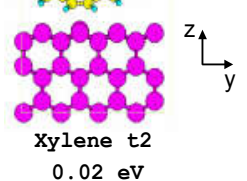

buceowe है?

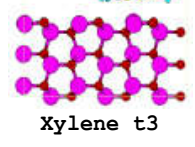

$0.20 \mathrm{eV}$

Figure 2. Relative energies of the three most stable adsorption configurations of (a) benzene, (b) toluene, (c) ethylbenzene and (d) xylene on $\mathrm{ZnO}(100)$ surface.

Table 2. Some important parameters from the adsorption energies of BTEX gases on $\mathrm{Zn}(100)$ surface.

\begin{tabular}{lcclc}
\hline Molecule & $\begin{array}{c}E_{a d} \\
(\mathrm{eV})\end{array}$ & $\begin{array}{c}d_{\text {surf-mol }} \\
(\AA)\end{array}$ & Bond-type & $\begin{array}{c}\Delta Q_{\text {mol }} \\
\left(\mathrm{e}^{-}\right)\end{array}$ \\
\hline Benzene & -0.96 & 2.085 & $\mathrm{O}^{\text {surf }}-\mathrm{H}^{\text {benzene }}$ & 0.09 \\
Toluene & -1.17 & 2.389 & $\mathrm{O}^{\text {surf }}-\mathrm{H}^{\text {benzene }}$ & 0.10 \\
Ethylbenzene & -1.16 & 2.142 & $\mathrm{O}^{\text {surf }}-\mathrm{H}^{\text {benzene }}$ & 0.09 \\
Xylene & -1.35 & 2.048 & $\mathrm{O}^{\text {surf }}-\mathrm{H}^{\text {benzene }}$ & 0.10 \\
\hline
\end{tabular}




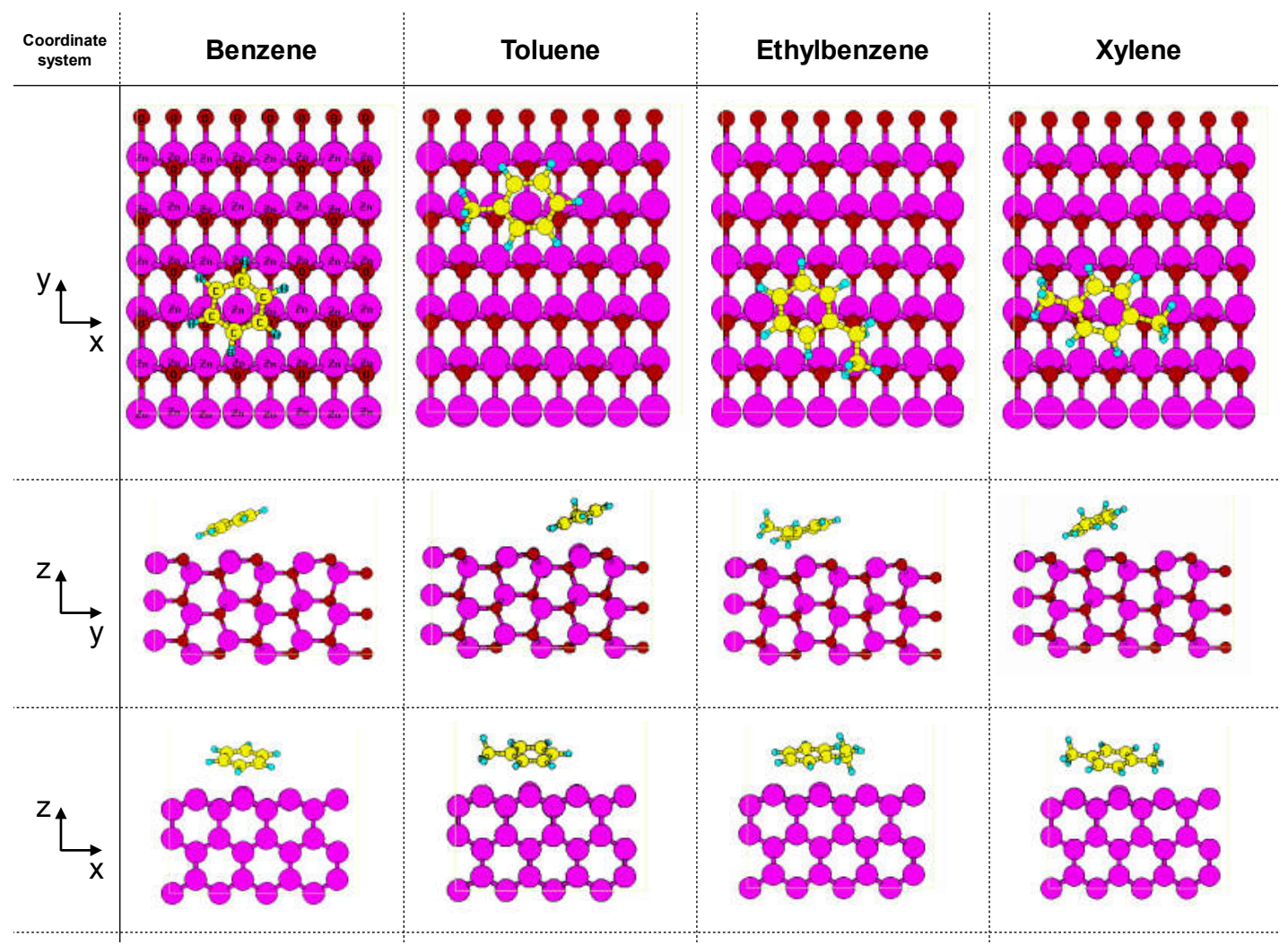

Figure 3. The configurations of the most stable BTEX adsorption on $\mathrm{ZnO}(100)$ surfaces.
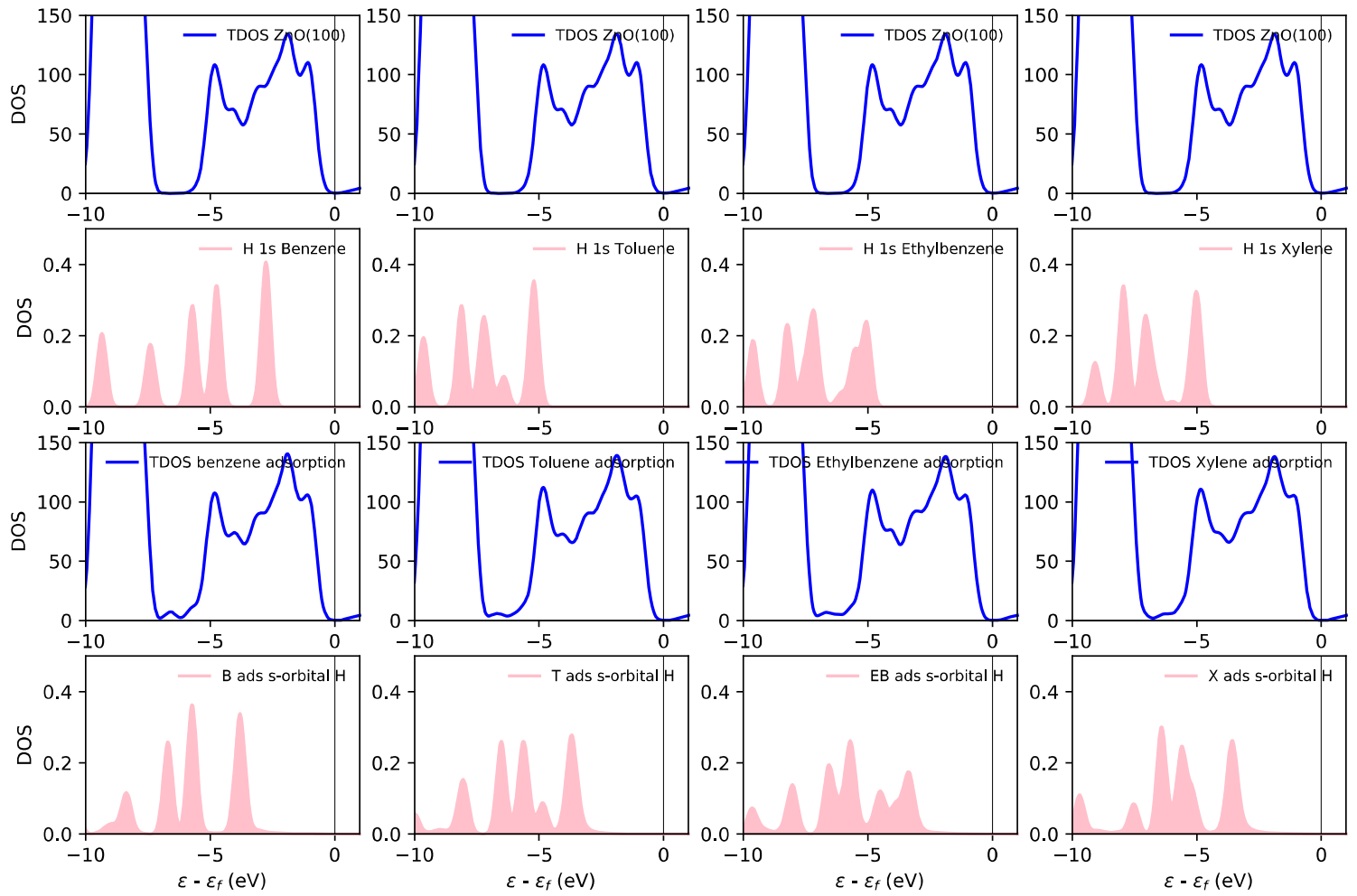

Figure 4. Total DOS and PDOS of BTEX adsorptions on $\mathrm{ZnO}(100)$ surface. 


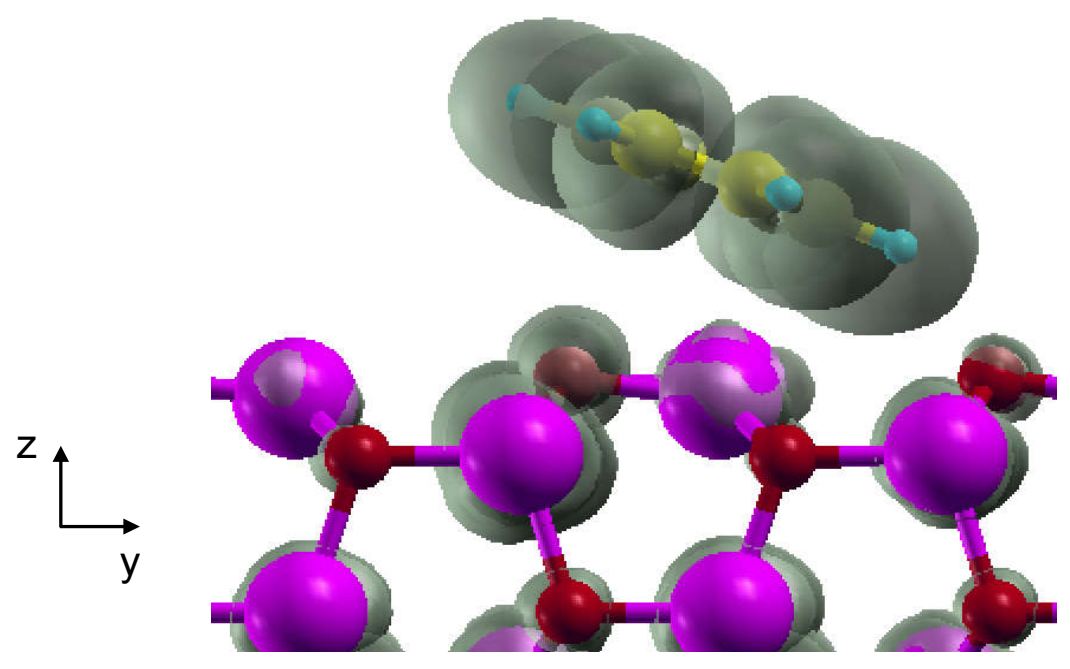

Figure 5. Partial charge density of benzene adsorption on $\mathrm{ZnO}(100)$ surface at energy around $-6 \mathrm{eV}$ relative to the Fermi level.

The electronic structures of BTEX molecules and $\mathrm{ZnO}(100)$ surface before and after the adsorption are summarized in Figure 4. From the total density of states (TDOS) of the system before and after adsorption (the first and third lines of Figure 4), we can see that there are no major change in the TDOSs of the systems after BTEX adsorptions occur, except for the appearance of small peaks at energy around $-6 \mathrm{eV}$ relative to the Fermi level. These peaks come from one of the molecular orbitals of BTEX molecules. We plot the projected density of states (PDOS) of $l s$ orbitals of $\mathrm{H}$ atom of the BTEX molecules that form a hydrogen bond with the $\mathrm{O}$ atom of the topmost layer of $\mathrm{ZnO}(100)$ before and after the adsorption occur in the second and fourth lines of Figure 4. From these data, we can see that the $1 s$ orbitals of the $\mathrm{H}$ atom of the adsorbed BTEX which directly interact with the topmost $\mathrm{ZnO}$ layer are only polarized and slightly shifted with respect to its isolated state. The profile of partial charges of benzene adsorption on $\mathrm{ZnO}(100)$ surface at energy around $-6 \mathrm{eV}$ is shown in Figure 5. This is the typical charge profiles for all of the BTEX adsorptions on $\mathrm{ZnO}(100)$ surface. We can clearly see that there are no obvious orbital overlapping between the benzene molecular orbitals and the surface states of $\mathrm{ZnO}(100)$ surface. It means that the appearance of new peaks at energy around $-6 \mathrm{eV}$ after the BTEX adsorptions occur really comes from the original molecular orbitals of BTEX molecules (a non-bonding state) and not from their hybridizations with the surface states of $\mathrm{ZnO}(100)$ surface. This suggests that the main mechanism for bonding in BTEX adsorptions on $\mathrm{ZnO}(100)$ surface are not originated from the orbital interaction between the BTEX and the surface, since there are no meaningful orbital hybridizations formed after the adsorption occur. Instead, the bonding comes from the contribution of van der Waals interaction between the surface and the molecule. Once again, this is a strong supporting evidence which shows that the BTEX adsorptions on $\mathrm{ZnO}(100)$ surface are indeed in a physisorption state.
The amount of charge transfer from BTEX-ZnO(100) interactions are also given in Table 3. The BTEX molecules act as donor and donates some of its electron to the $\mathrm{ZnO}$ surface, similar with the case of $\mathrm{CO}$ adsorption (Gurlo, 2006; Gurlo \& Riedel, 2007). However, in the case of BTEX adsorptions, the change in total charges of the molecules before and after the adsorption occurs $\left(\Delta Q_{\text {mol }}\right)$ are not so significant. The molecules only donate about $0.09-0.1 \mathrm{e}$ to the $\mathrm{ZnO}$ surface. The very low values of $\Delta Q_{\mathrm{mol}}$ indicate that the adsorbed BTEX molecules only weakly interact with the surface, consistent with the physisorption state of the BTEX-ZnO(100) systems.

In many chemisorption cases, normally, the trend of molecular adsorption can be properly explained by relating the trend of adsorption energy with the amount of charge transfer to/from the adsorbed molecule (Agusta, Saputro, Tanuwijaya, Hidayat, \& Dipojono, 2017; Nugraha et al., 2016, 2017; Rusydi, Agusta, Saputro, \& Kasai, 2012; A. G. Saputro et al., 2016; Adhitya G. Saputro \& Kasai, 2014; Adhitya G. Saputro, Kasai, Asazawa, Kishi, \& Tanaka, 2013; Adhitya G. Saputro et al., 2019). However, this procedure cannot be directly used in the current case since the amount of charge transfer in all BTEX adsorption cases are almost equivalent, and yet their adsorption energies are quite different. This is because, as mentioned before, the main mechanism that responsible for the BTEX adsorptions on $\mathrm{ZnO}(100)$ is the van der Waals interaction and not orbital interaction/hybridization. Therefore, the trend of BTEX adsorption energies must be explained by inspecting the expression of the van der Waals interaction which, in this study, is approximated by the semi-empirical dispersion correction of Grimme, DFT-D2 (Grimme, 2006).

The total energy of a system which is refined by a dispersion term can be expressed as $E_{\text {tot }}=E_{\text {tot }}^{G G A}+E_{\text {tot }}^{\text {disp }}$, where $E_{t o t}^{G G A}$ corresponds to the DFT total energy using GGA approximation and $E_{\text {tot }}^{\text {disp }}$ is the dispersion correction. By using this definition, the original expression of the adsorption energy in equation (1) can be rewritten as: 


$$
\begin{aligned}
E_{a d}=E_{a d}^{G G A}+E_{\text {ad }}^{\text {disp }} & =\left(E_{\text {system }}^{G G A}-E_{\text {surf }}^{G G A}-E_{\text {mol }}^{G G A}\right)+\left(E_{\text {system }}^{\text {disp }}-E_{\text {surf }}^{\text {disp }}-E_{\text {mol }}^{\text {disp }}\right) \\
& =E_{\text {ad }}^{G G A}+\left(\left(E_{\text {surf }- \text { mol } *}^{\text {disp }}+E_{\text {surf } *}^{\text {disp }}+E_{\text {mol* }}^{\text {disp }}\right)-E_{\text {surf }}^{\text {disp }}-E_{\text {mol }}^{\text {disp }}\right) \\
& =E_{\text {ad }}^{G G A}+E_{\text {surf }- \text { mol } *}^{\text {disp }}+\left\{\left(E_{\text {surf } *}^{\text {disp }}+E_{\text {mol } *}^{\text {disp }}\right)-E_{\text {surf }}^{\text {disp }}-E_{\text {mol }}^{\text {disp }}\right\},
\end{aligned}
$$

where $E_{\text {surf* }}^{\text {disp }}$ corresponds to the dispersion energy of the $\mathrm{ZnO}(100)$ surface in the adsorption system, $E_{\text {mol* }}^{\text {disp }}$ corresponds to the dispersion energy of the adsorbed molecule in the adsorption system and $E_{\text {surf-mol* }}^{\text {disp }}$ corresponds to the dispersion energy coming from the interaction between atoms in the adsorbed molecule and the $\mathrm{ZnO}(100)$ surface. If the structure of the $\mathrm{ZnO}(100)$ surface and the adsorbed molecule in the adsorption system do not significantly change relative to their isolated states, then the terms $\left\{\left(E_{\text {surf } *}^{\text {disp }}+E_{\text {mol } *}^{\text {disp }}\right)-E_{\text {surf }}^{\text {disp }}-E_{\text {mol }}^{\text {disp }}\right\}$ in equation (2) are practically cancelled. This leaves us with the following expression:

$$
E_{a d} \cong E_{a d}^{G G A}+E_{\text {surf-mol* }}^{\text {disp }}
$$

The dispersion energy within DFT-D2 approximation can be expressed by the following equation (Grimme, 2006):

$$
E_{\text {disp }}=-\frac{1}{2} \sum_{i=1}^{N a t} \sum_{j=1}^{N a t} \sum_{L}, \frac{C_{6 i j}}{r_{i j, L}^{6}} f_{d, 6}\left(r_{i j, L}\right),
$$

where the summations run over all atoms $N_{a t}$ and all translations of the unit cells. Since all of the BTEX adsorption systems consist of the same type of atoms (i.e. $\mathrm{Zn}, \mathrm{O}, \mathrm{C}$, and $\mathrm{H}$ ) and use the same exchange-correlation potentials, then the values of dispersion coefficients and scaling parameters are equivalent for all adsorption systems. Hence, the only things that differ are (1) the atomic distances $r_{i j, L}$ (which depend on the adsorption configurations) and (2) number of atoms $N_{a t}$ involved in the adsorption (which depend on the type of the adsorbed molecule). Even though the values of $r_{i j, L}$ are important, the $N_{a t}$ gives more dominant contributions to the value of $E_{\text {disp. }}$. The more atoms involved in the system, the more negative the value of $E_{\text {disp }}$. The same thing happen for the case of adsorption energy calculation. The more atoms involved in the interaction between in the adsorbed molecule and the $\mathrm{ZnO}(100)$ surface, the more negative the value of $E_{\text {surf-mol* }}^{\text {disp }}$, and according to equation (3), this will lead to a more negative (stronger) adsorption energy.

The above mechanism (equation (3)) can be used to rationalized the trend of adsorption energies of benzene, toluene and xylene on $\mathrm{ZnO}(100)$ in Table 2. The trend of the strength of adsorption energies is $\left|E_{\text {ad }}^{\text {benzene }}\right|<$
$\left|E_{\text {ad }}^{\text {toluene }}\right|<\left|E_{\text {ad }}^{\text {xylene }}\right|$ because $N_{a t}^{\text {benzene }}<N_{\text {at }}^{\text {toluene }}<$ $N_{a t}^{x y l e n e}$. However, this mechanism cannot properly explained the position of ethylbenzene adsorption in the trend since the adsorption energy of ethylbenzene (-1.16 $\mathrm{eV})$ is slightly weaker than that of toluene $(-1.17 \mathrm{eV})$, even though the number of atoms in toluene is less than that in ethylbenzene. The violation of this trend can be qualitatively explained by inspecting the adsorption structure of the BTEX molecules on $\mathrm{ZnO}(100)$ surface. The adsorption configurations of benzene, toluene and xylene molecules are quite similar due to their planar conformations. However, for the ethylbenzene case, there are two possible parallel adsorption configurations which are dictated by the orientation of its ethyl group (see Figure 2c). Our calculation shows that in its most stable adsorption configuration, the adsorbed ethylbenzene molecule energetically prefers the parallel adsorption configuration with its ethyl group facing slightly upward. To accommodate this adsorption configuration, the dihedral angle of the ethyl group of the ethylbenzene changes from $82.22^{\circ}$ in the isolated state into $36.37^{\circ}$ in the adsorbed state as presented in Figure 3. As we mentioned before, the terms $\left\{\left(E_{\text {surf } *}^{\text {disp }}+E_{\text {mol* }}^{\text {disp }}\right)-E_{\text {surf }}^{\text {disp }}-E_{\text {mol }}^{\text {disp }}\right\}$ in equation (2) only cancelled when the structure of the adsorbed molecule does not significantly changed relative to its isolated state. In ethylbenzene case, these terms do not cancelled since the dihedral angle of the molecule is greatly modified after the adsorption occur, even though the average bond distances within the molecule do not significantly change (see Table 3 ). The change in this dihedral angle increases the total energy and the dispersion energy of ethylbenzene with regards to its isolated molecule state. Due to this, the value of $\left\{\left(E_{\text {surf* }}^{\text {disp }}+\right.\right.$ $\left.\left.E_{\text {mol } *}^{\text {disp }}\right)-E_{\text {surf }}^{\text {disp }}-E_{\text {mol }}^{\text {disp }}\right\}$ in equation (2) for the case of ethylbenzene adsorption becomes positive since the $\left(E_{\text {surf } *}^{\text {disp }}-E_{\text {surf }}^{\text {disp }}\right)$ terms are practically cancelled. This makes the final adsorption energy of ethylbenzene become less negative (weaker). Therefore, the violation of the trend of BTEX adsorption energies is caused by the geometrical reconstruction of ethylbenzene upon its adsorption on $\mathrm{ZnO}(100)$ surface.

Table 3. The changes in average bond-lengths in BTEX gases before and after adsorption on $\mathrm{ZnO}(100)$ surface.

\begin{tabular}{lcccccc}
\hline Adsorbate & $\Delta(\mathrm{C}-\mathrm{C})^{\text {ave }}$ & $\Delta(\mathrm{C}-\mathrm{H})^{\mathrm{ave}}$ & $\Delta\left(\mathrm{C}^{\text {ben }}-\mathrm{C}^{\mathrm{CH} 2 / 3}\right)^{\mathrm{ave}}$ & $\Delta\left(\mathrm{C}-\mathrm{H}^{\mathrm{CH} 3}\right)^{\mathrm{ave}}$ & $\Delta\left(\mathrm{C}^{\mathrm{CH} 2}-\mathrm{C}^{\mathrm{CH} 3}\right)$ & \multicolumn{2}{c}{$\Delta\left(\mathrm{C}-\mathrm{H}^{\mathrm{CH} 2}\right)^{\mathrm{ave}}$} \\
& $(\AA)$ & $(\AA)$ & $(\AA)$ & - & - & - \\
\hline \hline Benzene & 0.002 & 0.001 & $\AA)$ & - & - & - \\
Toluene & 0.003 & 0.000 & -0.003 & 0.003 & -0.008 & 0.003 \\
Ethylbenzene & 0.004 & -0.001 & 0.006 & -0.002 & - & - \\
Xylene & 0.004 & 0.001 & -0.003 & 0.002 & - \\
\hline
\end{tabular}


Several experiments have reported about the sensitivity of $\mathrm{ZnO}$ material towards benzene, toluene and xylene (BTX) (Acharyya \& Bhattacharyya, 2015; Mirzaei et al., 2018; Nagaraju et al., 2018; Shen et al., 2018; Wang et al., 2013; Zhu et al., 2004). Even though the surface facet of the $\mathrm{ZnO}$ used in these experiments are not uniform, in most of the cases, the $\mathrm{ZnO}$ material always has large portions of (100) surface. In general, the sensitivities of $\mathrm{ZnO}$ towards BTX gases are in the following order: xylene $>$ tolune $>$ benzene. There are two well-known possible sensing mechanisms based on the ionosorption model (Gurlo \& Riedel, 2007). The first one only involves molecular adsorption on the sensing material while the second one involves reactions with ionic oxygen species on the surface. In the first ionosorption mechanism, the target molecule is adsorbed on the surface of the metal oxide and the change of surface electronic state during the adsorption is interpreted as the response of the sensor. Stronger molecular adsorption should lead to a stronger response. This mechanism can be used to relate our calculation results with the experimental results. The trend of the calculated BTX adsorption energies on $\mathrm{ZnO}(100)$ (see Table 2) is indeed in agreement with the trend of sensitivity for BTX gases on $\mathrm{ZnO}$ material (Acharyya \& Bhattacharyya, 2015; Mirzaei et al., 2018; Nagaraju et al., 2018; Shen et al., 2018; Wang et al., 2013; Zhu et al., 2004). This finding also suggests that (100) surface, being the most stable $\mathrm{ZnO}$ facet, might be one of the main surface facet that responsible for the detection of BTX gases. Unfortunately, we could not find the experimental comparison for ethylbenzene case. Based on the first ionosorption mechanism, we might predict that the response of $\mathrm{ZnO}$ towards ethylbenzene will be close to the response towards toluene since the values of their adsorption energies are very close.

To fully understand the trend of sensitivity of $\mathrm{ZnO}$ towards BTEX gases, we also need to study the second mechanism in the ionosorption model. In fact, the majority of experimental studies always rely on this mechanism to explain their results (Mirzaei et al., 2018). This sensing mechanism is more reliable since the reaction between the target molecule and the surface oxygens will induce a radical change in the electronic structure of the sensing material and hence producing a much stronger response than the first ionosorption mechanism. Unfortunately, our current results cannot be used to explain this mechanism since it requires additional calculations involving complex decomposition reactions. However, we might provide some insights from our results to improve the current model that might be used to study the second mechanism of ionosorption model.

In the second ionosorption mechanism, the adsorbed target molecule reacts with the ionic oxygens on the surface and forms new molecules. The change in the electronic structure of the surface during this reaction is interpreted as the response of the sensor. For the case of BTX gases, many experiment studies interpreted this mechanism as BTX decomposition reactions into $\mathrm{CO}_{2}$ and $\mathrm{H}_{2} \mathrm{O}$ through: $\mathrm{C}_{m} \mathrm{H}_{n}+x \mathrm{O}^{-y} \rightarrow \mathrm{mCO}_{2}+\frac{n}{2} \mathrm{H}_{2} \mathrm{O}+$ $x y e^{-}$(Acharyya \& Bhattacharyya, 2015; Mirzaei et al., 2018; Nagaraju et al., 2018; Shen et al., 2018; Wang et al.,
2013; Zhu et al., 2004). This decomposition is initiated by the dehydrogenation of the benzene ring or the methyl group. The initial state of a dehydrogenation reaction of a hydrocarbon molecule is usually indicated by the elongation of its $\mathrm{C}-\mathrm{H}$ bonds. Without proper $\mathrm{C}-\mathrm{H}$ elongation, the activation energy required for the dehydrogenation will be very high. Therefore, we should check the $\mathrm{C}-\mathrm{H}$ elongation for BTEX adsorptions on $\mathrm{ZnO}(100)$ surface. The average in the change of $\mathrm{C}-\mathrm{H}$ bonds in benzene ring, ethyl and methyl groups of BTEX before and after the adsorption are presented on Table 3. From these data we can see that the changes in $\mathrm{C}-\mathrm{H}$ bonds after adsorption occur are very insignificant. This suggests that the dehydrogenation reaction, which is the signature of the second ionosorption mechanism, might not proceed on the perfect $\mathrm{ZnO}(100)$ surface since the initial $\mathrm{C}-\mathrm{H}$ elongation might require a quite high activation energy. This means that the second ionosorption mechanism require different $\mathrm{ZnO}$ surface configurations. For example, the perfect $\mathrm{ZnO}(100)$ surface might require additional adsorbed oxygen atoms or their combination with surface oxygen vacancies to induce $\mathrm{C}-\mathrm{H}$ elongation in the adsorbed BTEX molecules. This interaction will be discussed in our future publication.

\section{CONCLUSIONS}

We study the adsorption of benzene, toluene, ethylbenzene and xylene (BTEX) molecules on $\mathrm{ZnO}(100)$ surface using density functional theory-based calculations. We find that the inclusion of dispersion correction is very crucial for studying the trend of BTEX adsorption energies. We find that the BTEX molecules are physisorbed on the $\mathrm{ZnO}(100)$ surface with parallel configurations and adsorption distances larger than $2 \AA$. The van der Waals interaction dominates over covalent interaction in the adsorption mechanism of BTEX on $\mathrm{ZnO}(100)$ surface. We also find that the trend of the strength of BTX adsorptions is in line with the experimental trend of $\mathrm{ZnO}$ sensitivity towards BTX gases based on the adsorption-based sensing mechanism, which is one of the well-known sensing mechanism within the ionosorption model. Even though there is no available experimental data for verifying the position of ethylbenzene in the sensitivity trend, based on the trend of adsorption energy, we might predict that the response of $\mathrm{ZnO}$ towards ethylbenzene will be similar to the response towards toluene.

\section{ACKNOWLEDGEMENTS}

This work is funded by the Osaka Gas Foundation of International Cultural Exchange (OGFICE) 2018 program. Some of calculations were performed using high performance computing facility in Research Center for Nanosciences and Nanotechnology, Institut Teknologi Bandung.

\section{REFERENCES}

Acharyya, D., \& Bhattacharyya, P. (2015). An efficient BTX sensor based on $\mathrm{ZnO}$ nanoflowers grown by CBD method. Solid-State Electronics, 106, 18-26. https://doi.org/10.1016/j.sse.2014.12.027

Agusta, M. K., Saputro, A. G., Tanuwijaya, V. V., Hidayat, N. N., \& Dipojono, H. K. (2017). Hydrogen 
Adsorption on Fe-based Metal Organic Frameworks: DFT Study. Procedia Engineering, 170, 136-140.

https://doi.org/10.1016/j.proeng.2017.03.030

Blöchl, P. E. (1994). Projector augmented-wave method. Phys. Rev. B, 50(24), 17953-17979. https://doi.org/10.1103/PhysRevB.50.17953

Brook, R. D. (2008). Cardiovascular effects of air pollution. Clinical Science, 115(6), 175 LP-187. https://doi.org/10.1042/CS20070444

Debataraja, A., Muchtar, A. R., Septiani, N. L. W., Yuliarto, B., Nugrahaauth, \& Sunendar, B. (2017). High Performance Carbon Monoxide Sensor Based on Nano Composite of SnO2-Graphene. IEEE Sensors Journal, 17(24), 8297-8305. https://doi.org/10.1109/JSEN.2017.2764088

Diebold, U., Koplitz, L. V., \& Dulub, O. (2004). Atomicscale properties of low-index $\mathrm{ZnO}$ surfaces. Applied Surface Science, 237(1-4), 336-342. https://doi.org/10.1016/S0169-4332(04)00985-7

Duarte, R, D., C, C., \& L, R. (2001). Benzene in the environment: an assessment of the potential risks to the health of the population. Occupational and Environmental Medicine, 58(1), 2-13. https://doi.org/10.1136/oem.58.1.2

Dzade, N., Roldan, A., \& de Leeuw, N. (2014). A Density Functional Theory Study of the Adsorption of Benzene on Hematite $(\alpha-\mathrm{Fe} 2 \mathrm{O} 3)$ Surfaces. Minerals, 4(1), 89-115. https://doi.org/10.3390/min4010089

Erhart, P., Albe, K., \& Klein, A. (2006). First-principles study of intrinsic point defects in $\mathrm{ZnO}$ : Role of band structure, volume relaxation, and finite-size effects. Physical Review B - Condensed Matter and Materials Physics, 73(20), 205203. https://doi.org/10.1103/PhysRevB.73.205203

Fishbein, L. (1985). An overview of environmental and toxicological aspects of aromatic hydrocarbons IV. Ethylbenzene. Science of The Total Environment, 44(3), 269-287. https://doi.org/https://doi.org/10.1016/00489697(85)90100-7

Giannozzi, P., Baroni, S., Bonini, N., Calandra, M., Car, R., Cavazzoni, C., ... Wentzcovitch, R. M. (2009). QUANTUM ESPRESSO: A modular and opensource software project for quantum simulations of materials. Journal of Physics Condensed Matter, 21(39). $8984 / 21 / 39 / 395502$

Gist, G. L., \& Burg, J. R. (1997). Benzene-a Review of the Literature from a Health Effects Perspective. Toxicology and Industrial Health, 13(6), 661-714. https://doi.org/10.1177/074823379701300601

Grimme, S. (2006). Semiempirical GGA-type density functional constructed with a long-range dispersion correction. Journal of Computational Chemistry, 27(15),

$1787-1799$ https://doi.org/10.1002/jcc.20495

Gromiec, J. P., \& Piotrowski, J. K. (1984). Urinary mandelic acid as an exposure test for ethylbenzene. International Archives of Occupational and
Environmental Health, 55(1), 61-72. https://doi.org/10.1007/BF00378068

Gurlo, A. (2006). Interplay between $\mathrm{O} 2$ and $\mathrm{SnO} 2$ : Oxygen ionosorption and spectroscopic evidence for adsorbed oxygen. ChemPhysChem, 7(10), 20412052. https://doi.org/10.1002/cphc. 200600292

Gurlo, A., \& Riedel, R. (2007). In situ and operando spectroscopy for assessing mechanisms of gas sensing. Angewandte Chemie - International Edition, 46(21), 3826-3848. https://doi.org/10.1002/anie.200602597

Hohenberg, P., \& Kohn, W. (1964). Inhomogeneous electron gas. Physical Review, 136(3B), B864 B871. https://doi.org/10.1103/PhysRev.136.B864

Huang, J., \& Wan, Q. (2009). Gas sensors based on semiconducting metal oxide one-dimensional nanostructures. Sensors, 9(12), 9903-9924. https://doi.org/10.3390/s91209903

Iqbal, M., Marintan, E., Septiani, N. L. W., Suyatman, Nuruddin, A., Nugraha, \& Yuliarto, B. (2014). Synthesis and Harmful Gas Sensing Properties of Zinc Oxide Modified Multi-Walled Carbon Nanotubes Composites. Advanced Materials Research, 1044-1045, 172-175. https://doi.org/10.4028/www.scientific.net/AMR.1 044-1045.172

Jeong, S.-Y., Yoon, J.-W., Kim, T.-H., Jeong, H.-M., Lee, C.-S., Chan Kang, Y., \& Lee, J.-H. (2017). Ultraselective detection of sub-ppm-level benzene using $\mathrm{Pd}-\mathrm{SnO} 2$ yolk-shell micro-reactors with a catalytic $\mathrm{Co} 3 \mathrm{O} 4$ overlayer for monitoring air quality. Journal of Materials Chemistry A, 5(4),1446-1454. https://doi.org/10.1039/C6TA09397C

Jung, J. Y., Park, J. H., Jeong, Y. J., Yang, K. H., Choi, N. K., Kim, S. H., \& Kim, W. J. (2006). Involvement of Bcl-2 family and caspases cascade in sodium fluoride-induced apoptosis of human gingival fibroblasts. Korean Journal of Physiology and Pharmacology, 10(5), 289-295. https://doi.org/10.1103/PhysRev.140.A1133

Kaneti, Y. V., Yue, J., Jiang, X., \& Yu, A. (2013). Controllable synthesis of $\mathrm{ZnO}$ nanoflakes with exposed (1010) for enhanced gas sensing performance. Journal of Physical Chemistry C, $117(25)$, https://doi.org/10.1021/jp404329q

Kim, H. S. D., Yang, J., Qi, Y., \& Rappe, A. M. (2017). Adsorption of benzene on the RuO2(110) Surface. Journal of Physical Chemistry C, 121(3), 15851590. https://doi.org/10.1021/acs.jpcc.6b08236

Kim, K. H., Pandey, S. K., \& Pal, R. (2009). Analytical bias among different gas chromatographic approaches using standard BTX gases and exhaust samples. Journal of Separation Science, 32(4), 549-558. https://doi.org/10.1002/jssc.200800556

Kohn, W., \& Sham, L. J. (1965). Self-Consistent Equations Including Exchange and Correlation Effects. Phys. Rev., 140(4A), A1133-A1138. https://doi.org/10.1103/PhysRev.140.A1133

Kokalj, A. (2003). Computer graphics and graphical user interfaces as tools in simulations of matter at the 
atomic scale. Computational Materials Science, $28(2)$, $155-168$. https://doi.org/https://doi.org/10.1016/S09270256(03)00104-6

Lakshmikanth, K. G., Ayishabi, P. K., \& Chatanathodi, R. (2017). Ab initio DFT studies of adsorption characteristics of benzene on close-packed surfaces of transition metals. Computational Materials Science, 137, 10-19. https://doi.org/10.1016/j.commatsci.2017.05.019

Liu, W., Ruiz, V. G., Zhang, G. X., Santra, B., Ren, X., Scheffler, M., \& Tkatchenko, A. (2013). Structure and energetics of benzene adsorbed on transitionmetal surfaces: Density-functional theory with van der Waals interactions including collective substrate response. New Journal of Physics, 15, 127. 2630/15/5/053046

Liu, W., Tkatchenko, A., \& Scheffler, M. (2014). Modeling adsorption and reactions of organic molecules at metal surfaces. Accounts of Chemical Research, 47(11), 3369-3377. https://doi.org/10.1021/ar500118y

Miller, D. R., Akbar, S. A., \& Morris, P. A. (2014). Nanoscale metal oxide-based heterojunctions for gas sensing: A review. Sensors and Actuators, B: Chemical, 204, 250-272. https://doi.org/10.1016/j.snb.2014.07.074

Mirzaei, A., Kim, J. H., Kim, H. W., \& Kim, S. S. (2018). Resistive-based gas sensors for detection of benzene, toluene and xylene (BTX) gases: A review. Journal of Materials Chemistry C, 6(16), 43424370. https://doi.org/10.1039/c8tc00245b

Muchtar, A. R., Septiani, N. L. W., Iqbal, M., Nuruddin, A., \& Yuliarto, B. (2018). Preparation of Graphene-Zinc Oxide Nanostructure Composite for Carbon Monoxide Gas Sensing. Journal of Electronic Materials, 47(7), 3647-3656. https://doi.org/10.1007/s11664-018-6213-x

Nagaraju, P., Vijayakumar, Y., Reddy, G. L. N., \& Ramana Reddy, M. V. (2018). ZnO wrinkled nanostructures: enhanced BTX sensing. Journal of Materials Science: Materials in Electronics, 29(13), 1145711465. https://doi.org/10.1007/s10854-018-9238-2

Nugraha, Saputro, A. G., Agusta, M. K., Yuliarto, B., Dipojono, H. K., \& Maezono, R. (2016). Density functional study of adsorptions of $\mathrm{CO} 2$, NO2and SO2molecules on $\mathrm{Zn}(0002)$ surfaces. Journal of Physics: Conference Series, 739(1). https://doi.org/10.1088/1742-6596/739/1/012080

Nugraha, Saputro, A. G., Agusta, M. K., Yuliarto, B., Dipojono, H. K., Rusydi, F., \& Maezono, R. (2017). Selectivity of $\mathrm{CO}$ and $\mathrm{NO}$ adsorption on $\mathrm{ZnO}$ (0002) surfaces: A DFT investigation. Applied Surface Science, 410, 373-382. https://doi.org/https://doi.org/10.1016/j.apsusc.201 7.03.009

Perdew, J. P., Burke, K., \& Ernzerhof, M. (1996a). Generalized gradient approximation made simple. Physical Review Letters, 77(18), 3865-3868. https://doi.org/10.1103/PhysRevLett.77.3865

Perdew, J. P., Burke, K., \& Ernzerhof, M. (1996b).
Generalized gradient approximation made simple. Physical Review Letters, 77(18), 3865-3868. https://doi.org/10.1103/PhysRevLett.77.3865

Pyta, H. (2006). BTX air pollution in Zabrze, Poland. Polish Journal of Environmental Studies, 15(5), 785-791.

Reckien, W., Eggers, M., \& Bredow, T. (2014). Theoretical study of the adsorption of benzene on coinage metals. Beilstein Journal of Organic Chemistry, 10, 1775-1784. https://doi.org/10.3762/bjoc. 10.185

Rifai, A., Iqbal, M., Nugraha, Nuruddin, A., Suyatman, \& Yuliarto, B. (2011). Synthesis and characterization of $\mathrm{SnO} 2$ thin films by chemical bath deposition. AIP Conference Proceedings, 1415(1), 231-233. https://doi.org/10.1063/1.3667263

Robert Schnatter, A., Kerzic, P. J., Zhou, Y., Chen, M., Nicolich, M. J., Lavelle, K., ... Irons, R. D. (2010). Peripheral blood effects in benzene-exposed workers. Chemico-Biological Interactions, 184(1), 174-181. https://doi.org/https://doi.org/10.1016/j.cbi.2009.1 2.020

Rusydi, F., Agusta, M. K., Saputro, A. G., \& Kasai, H. (2012). A first principles study on zinc-porphyrin interaction with O2in zinc-porphyrin(oxygen) complex. Journal of the Physical Society of Japan, 81(12),

124301/1-11. https://doi.org/10.1143/JPSJ.81.124301

Sabbe, M. K., Laín, L., Reyniers, M. F., \& Marin, G. B. (2013). Benzene adsorption on binary Pt3M alloys and surface alloys: A DFT study. Physical Chemistry Chemical Physics, 15(29), 12197-12214. https://doi.org/10.1039/c3cp50617g

Saputro, A. G., Agusta, M. K., Wungu, T. D. K., Suprijadi, Rusydi, F., \& Dipojono, H. K. (2016). DFT study of adsorption of CO2on palladium cluster doped by transition metal. In Journal of Physics: Conference Series (Vol. 739). https://doi.org/10.1088/1742$6596 / 739 / 1 / 012083$

Saputro, A. G., \& Kasai, H. (2014). Density functional theory study on the interaction of $\mathrm{O} 2$ and $\mathrm{H} 2 \mathrm{O} 2$ molecules with the active sites of cobaltpolypyrrole catalyst. Journal of the Physical Society of Japan, 83(2), 1-11. https://doi.org/10.7566/JPSJ.83.024707

Saputro, A. G., Kasai, H., Asazawa, K., Kishi, H., \& Tanaka, H. (2013). Comparative study on the catalytic activity of the TM-N2 active sites (TM = $\mathrm{Mn}, \mathrm{Fe}, \mathrm{Co}, \mathrm{Ni}$ ) in the oxygen reduction reaction: Density functional theory study. Journal of the Physical Society of Japan, 82(11), 1-11. https://doi.org/10.7566/JPSJ.82.114704

Saputro, A. G., Putra, R. I. D., Maulana, A. L., Karami, M. U., Pradana, M. R., Agusta, M. K., ... Kasai, H. (2019). Theoretical study of CO2 hydrogenation to methanol on isolated small Pdx clusters. Journal of Energy Chemistry, 35, 79-87. https://doi.org/10.1016/j.jechem.2018.11.005

Septiani, N. L. W., Kaneti, Y. V., Yuliarto, B., Nugraha, Dipojono, H. K., Takei, T., ... Yamauchi, Y. (2018). Hybrid nanoarchitecturing of hierarchical zinc 
oxide wool-ball-like nanostructures with multiwalled carbon nanotubes for achieving sensitive and selective detection of sulfur dioxide. Sensors and Actuators, B: Chemical, 261, 241-251. https://doi.org/10.1016/j.snb.2018.01.088

Septiani, N. L. W., \& Yuliarto, B. (2016). Review-The Development of Gas Sensor Based on Carbon Nanotubes. Journal of The Electrochemical Society, 163(3),

B97-B106. https://doi.org/10.1149/2.0591603jes

Septiani, N. L. W., Yuliarto, B., Iqbal, M., Suyatman, Nuruddin, A., \& Nugraha. (2015). The Methanol Response Sensing Properties Using MWCNT-ZnO Composite. Advanced Materials Research, 1112, 116-119.

https://doi.org/10.4028/www.scientific.net/AMR.1 112.116

Septiani, N. L. W., Yuliarto, B., Nugraha, \& Dipojono, H. K. (2017). Multiwalled carbon nanotubes-zinc oxide nanocomposites as low temperature toluene gas sensor. Applied Physics A: Materials Science and Processing, 123(3), https://doi.org/10.1007/s00339-017-0803-y

Shen, Z., Zhang, X., Ma, X., Mi, R., Chen, Y., \& Ruan, S. (2018). The significant improvement for BTX (benzene, toluene and xylene) sensing performance based on Au-decorated hierarchical $\mathrm{ZnO}$ porous rose-like architectures. Sensors and Actuators, B: Chemical, 262, 86-94. https://doi.org/10.1016/j.snb.2018.01.205

Spencer, M. J. S., Wong, K. W. J., \& Yarovsky, I. (2012). Surface defects on $\mathrm{ZnO}$ nanowires: Implications for design of sensors. Journal of Physics Condensed Matter, 24(30). https://doi.org/10.1088/0953$8984 / 24 / 30 / 305001$

Szczurek, A., Maziejuk, M., Maciejewska, M., Pietrucha, T., \& Sikora, T. (2017). BTX compounds recognition in humid air using differential ion mobility spectrometry combined with a classifier. Sensors and Actuators, B: Chemical, 240, 12371244. https://doi.org/10.1016/j.snb.2016.08.164

Tang, Q.-L., \& Luo, Q.-H. (2013). Adsorption of CO2 at $\mathrm{ZnO}$ : A Surface Structure Effect from DFT $+\mathrm{U}$ Calculations. The Journal of Physical Chemistry C, 117(44), 22954-22966. https://doi.org/10.1021/jp407970a

Waldmann, T., Nenon, C., Tonigold, K., Hoster, H. E., Groß, A., \& Behm, R. J. (2012). The role of surface defects in large organic molecule adsorption: Substrate configuration effects. Physical Chemistry Chemical Physics, 14(30), 10726-10731. https://doi.org/10.1039/c2cp40800g

Wang, L., Wang, S., Xu, M., Hu, X., Zhang, H., Wang, Y., \& Huang, W. (2013). A Au-functionalized $\mathrm{ZnO}$ nanowire gas sensor for detection of benzene and toluene. Physical Chemistry Chemical Physics, 15(40), 17179-17186.
https://doi.org/10.1039/C3CP52392F

Woo, H. S., Kwak, C. H., Chung, J. H., \& Lee, J. H. (2014). Co-doped branched $\mathrm{ZnO}$ nanowires for ultraselective and sensitive detection of xylene. ACS Applied Materials and Interfaces, 6(24), 22553-22560. https://doi.org/10.1021/am506674u

Xu, H., Zhang, R. Q., \& Tong, S. Y. (2010). Interaction of $\mathrm{O} 2, \mathrm{H} 2 \mathrm{O}, \mathrm{N} 2$, and $\mathrm{O} 3$ with stoichiometric and reduced $\mathrm{ZnO}(10$ 10) surface. Physical Review $B$, $82(15)$,

155326. https://doi.org/10.1103/PhysRevB.82.155326

Yan, Y., Al-Jassim, M. M., \& Wei, S. H. (2005). Oxygenvacancy mediated adsorption and reactions of molecular oxygen on the $\mathrm{ZnO}(1010)$ surface. Physical Review B - Condensed Matter and Materials Physics, 72(16), 161307. https://doi.org/10.1103/PhysRevB.72.161307

Yang, J., Qi, Y., Kim, H. D., \& Rappe, A. M. (2018). Mechanism of Benzene Tribopolymerization on the RuO2 (110) Surface. Physical Review Applied, 9(4), $1-6$. https://doi.org/10.1103/PhysRevApplied.9.044038

Yildirim, H., Greber, T., \& Kara, A. (2013). Trends in adsorption characteristics of benzene on transition metal surfaces: Role of surface chemistry and van der Waals interactions. Journal of Physical Chemistry C, 117(40), 20572-20583. https://doi.org/10.1021/jp404487z

Yuliarto, B., Gumilar, G., \& Septiani, N. L. W. (2015). $\mathrm{SnO} 2$ nanostructure as pollutant gas sensors: Synthesis, sensing performances, and mechanism. Advances in Materials Science and Engineering, 2015.

Yuliarto, B., Iqbal, M., \& Nuruddin, A. (2013). Synthesis of Various Nanostructures $\mathrm{ZnO}$ and its Applications for Gas Sensors. Advanced Materials Research, 629, 302-308. https://doi.org/10.4028/www.scientific.net/AMR.6 29.302

Yuliarto, B., Nulhakim, L., Ramadhani, M. F., Iqbal, M., Nugraha, Suyatman, \& Nuruddin, A. (2015). Improved performances of ethanol sensor fabricated on Al-doped $\mathrm{ZnO}$ nanosheet thin films. IEEE Sensors Journal, 15(7), 4114-4120. https://doi.org/10.1109/JSEN.2015.2410995

Yuliarto, B., Ramadhani, M. F., Nugraha, Septiani, N. L. W., \& Hamam, K. A. (2017). Enhancement of SO2gas sensing performance using $\mathrm{ZnO}$ nanorod thin films: the role of deposition time. Journal of Materials Science, 52(8), 4543-4554. https://doi.org/10.1007/s10853-016-0699-5

Zhu, B. L., Xie, C. S., Wang, W. Y., Huang, K. J., \& Hu, J. H. (2004). Improvement in gas sensitivity of $\mathrm{ZnO}$ thick film to volatile organic compounds (VOCs) by adding TiO2. Materials Letters, 58(5), 624-629. https://doi.org/10.1016/S0167-577X(03)00582-2 